DOI: 10.12731/2070-7568-2020-3-35-51

УДК 336.4

\title{
ИНВЕСТИЦИОННАЯ ПРИВЛЕКАТЕЛЬНОСТЬ РЕАЛИЗУЕМЫХ В КРАСНОЯРСКОМ КРАЕ НАЦИОНАЛЬНЫХ ПРОЕКТОВ
}

\author{
Бутакова Н.М., Кудашкин И.В.
}

Проблема неравномерности социально-экономического развития российских регионов на данный момент все ещзе актуальна. Некоторые регионы имеют развитую экономическую систему. Другие субъекты РФ испытывают трудности в собственном экономическом развитии. Уравнять социально-экономическое положение регионов должен комплекс национальных проектов, предложенных Президентом РФ. Реализация проектов возложена на федеральные и региональные органы власти, при этом часть средств на выполнение национальных проектов должны быть привлечена из частного капитала. В настоящей статье проанализирована категория «инвестиционная привлекательность», дана авторская трактовка понятия. Рассмотрен потенциил национальных проектов для развития субъектов РФ. На примере Красноярского края исследована привлекательность проектов для участия частных инвесторов в их реализации на территории региона.

Цель: обоснование необходимости повышения инвестиционной привлекательности региона на примере Красноярского края для частного капитала на основе анализа исполнения национальных проектов.

Метод или методология проведения работы: в статье использовались общенаучные подходы теоретического исследования: описание, изложение, анализа и синтеза.

Результаты: предложено авторское понимание «инвестиционной привлекательности». Выделены конкурентные стороны Красноярского края для привлечения инвесторов в регион. Исследован 
потенциал государственно-частного партнерства для выполнения национальных проектов в субъекте, рассмотрены преимущества реализации проектов для бизнеса: налоговые льготы, выход на новые рынки сбыта товаров и услуга и т.д.

Область применения результатов: проведеннье исследования могут использоваться для повышения инвестиционной привлекательности региона и более эффективной реализаџии наџиональных проектов.

Ключевые слова: инвестиционная привлекательность; национальные проекты; государственно-частное партнёрство; региональная экономика; инвестиции.

\section{INVESTMENT ATTRACTIVENESS OF NATIONAL PROJECTS IMPLEMENTED IN KRASNOYARSK REGION}

\section{Butakova N.M., Kudashkin I.V.}

The problem of uneven socio-economic development of the Russian regions is still relevant at the moment. Some regions have a developed economic system. Other subjects of the Russian Federation are experiencing difficulties in their own economic development. A set of national projects proposed by the President of the Russian Federation should equalize the socio-economic situation of the regions. The implementation of projects is entrusted to federal and regional authorities, while part of the funds for the implementation of national projects should be raised from private capital. In this article, the category "investment attractiveness" is analysed, the author's interpretation of the concept is given. The potential of national projects for the development of the constituent entities of the Russian Federation was considered. On the example of Krasnoyarsk territory, the attractiveness of projects for the participation of private investors in their implementation in the region was investigated.

The purpose of the work is to analyse national projects and their investment attractiveness for private capital participation in projects. 
The method or methodology of work: the article used general scientific approaches of theoretical research: description, presentation, analysis and synthesis.

Results: an author's understanding of "investment attractiveness" has been proposed. The competitive parties of Krasnoyarsk territory were allocated to attract investors to the region. The potential of public-private partnership for region implementation of national projects in the subject was investigated, the advantages of implementing projects for business were considered: tax incentives, access to new markets for goods and services and so on.

Scope of results: the research conducted can be used to increase the investment attractiveness of the region and more effective implementation of national projects.

Keywords: investment attractiveness; national projects; public-private partnership; regional economy, investments.

\section{Введение}

На сегодняшний момент времени в условиях стремительного развития общества, технологий и экономики, инвестиции являются важным ресурсом для достижения благоприятного социально-экономического развития территории. Обеспечение стабильного притока данных средств является важной задачей государственной политики в инвестиционной сфере. При этом борьба за привлечение частного капитала ограничивается комплексом определенных условий, среди которых, например, выступает инвестиционная привлекательность территории. Поэтому властям той или иной территории необходимо создавать условия, позволяющие привлекать инвесторов и заниматься развитием бизнеса.

Целью настоящей работы является обоснование необходимости повышения инвестиционной привлекательности региона на примере Красноярского края для частного капитала на основе анализа исполнения национальных проектов.

Исследование процесса реализации национальных проектов на территории Красноярского края и его связи с инвестиционной привлекательностью является основной задачей представленного труда. 


\section{Методология исследования}

В данной работе основным методом получения необходимой информации стало рассмотрение материалов из научных журналов, Интернет-ресурсов, климата статистических сборников. В процессе работы для систематизации анализируемой информации были применены общенаучные подходы теоретического исследования.

\section{Результаты и обсуждение}

Исследуем подробно понятие инвестиционной привлекательности региона. Существует ряд трактовок определения представленного понятия как экономической категории.

Так, В.А. Джиоев рассматривает инвестиционную привлекательность региона как состояние экономики, которое состоит из действующего инвестиционного и определенных рисков, а также из базовых условий, которые не поддаются изменению и оказывают значительное влияние на решение потенциальных инвесторов [3]. Автор предлагает повышать уровень инвестиционной привлекательности региона посредством проводимой федеральным и региональным руководством политики, способствующей снижению инвестиционных рисков и улучшению инвестиционного климата региона.

В свою очередь О.А. Мустафокулов считает, что инвестиционная привлекательность состоит из объективно сложившихся условий экономического развития региона и политики региональных властей в сфере привлечения инвестиций [15]. Исследователь предполагает, что для качественного улучшения инвестиционной привлекательности, региональным властям необходимо проводить аналитическую работу, направленную на повышение эффективности ведения инвестиционной деятельности в регионе. Такой анализ, как отмечает Мустафокулов, возможно проводить при помощи рейтинговых методов оценки региональной инвестиционной привлекательности.

По мнению Н.Ю. Жуковой и Е.В. Цыкаревой, привлекательность территории для потенциальных инвесторов складывается из таких параметров, как экономические возможности территории, инфраструктурные возможности и инвестиционный климат региона [5]. 
Последнее можно охарактеризовать как совокупность сложившихся политических, социально-культурных, финансово-экономических и правовых условий, определяющих качество предпринимательской инфраструктуры, эффективность инвестирования и степень возможных рисков при вложении капитала.

Исходя из вышеперечисленных определений, можно предложить авторскую трактовку понятия «инвестиционная привлекательность». По мнению авторов, это совокупность факторов, которые характеризуют социально-экономическое развитие территории, уровень инвестиционного климата региона, качество региональной политики в области привлечения инвестиций, а также степень инвестиционных рисков территории. Инвестиционная привлекательность позволяет формировать интерес у потенциальных инвесторов вкладываться в развитие территории. Чем привлекательнее будет регион для частного капитала, тем соответственно больший объем вложений удастся получить для социально-экономического прогресса территории.

Инвестиционный климат и инвестиционная привлекательность составляют важную основу для формирования благоприятных условий, исходя из которых, создаются предпосылки для притока инвесторов в регион. При этом если инвестиционная привлекательность по большей части представлена постоянными факторами, то инвестиционный климат - это результат проводимой региональными властями инвестиционной политики. Эффективная политика в сфере инвестирования позволяет создавать благоприятный инвестиционный климат.

Политика в инвестиционной сфере, являясь частью финансовой и экономических политик, направлена на улучшение экономического положения территории и повышения благосостояния населения посредством реализации национальных проектов.

Национальные проекты представляют собой план мероприятий федерального масштаба, утвержденный указом Президента РФ «О национальных целях и стратегических задачах развития Российской Федерации на период до 2024 года». Данные проекты предназначе- 
ны для осуществления масштабных целей в развитии экономики, социальной сферы, науки, культуры и спорта, цель которых - поднять уровень благосостояния наших граждан, обеспечить доступность и качество образования, здравоохранения, поддержать семью, снизить уровень бедности [1].

Всего в нормативных документах Правительства России указано 13 национальных проектов по трем основным направлениям, приведенных в табл. 1.

Таблицуа 1.

Национальные проекты Российской Федерации

\begin{tabular}{|c|c|c|}
\hline \multicolumn{3}{|c|}{ Направление } \\
\hline $\begin{array}{c}\text { Человеческий } \\
\text { капитал }\end{array}$ & $\begin{array}{c}\text { Комфортная среда } \\
\text { для жизни }\end{array}$ & Экономический рост \\
\hline \multicolumn{3}{|c|}{ Национальные проекты } \\
\hline $\begin{array}{l}\text { Здравоохране- } \\
\text { ние }\end{array}$ & $\begin{array}{l}\text { Безопасные и каче- } \\
\text { ственные автомо- } \\
\text { бильные дороги }\end{array}$ & Наука \\
\hline Образование & $\begin{array}{l}\text { Жильё и городская } \\
\text { среда }\end{array}$ & $\begin{array}{l}\text { Малое и среднее предприниматель- } \\
\text { ство и поддержка индивидуальной } \\
\text { предпринимательской инициативы }\end{array}$ \\
\hline Культура & Экология & Цифровая экономика \\
\hline \multirow[t]{3}{*}{ Демография } & & $\begin{array}{l}\text { Производительность труда и поддерж- } \\
\text { ка занятости }\end{array}$ \\
\hline & & Международная кооперация и экспорт \\
\hline & & $\begin{array}{l}\text { Комплексный план модернизации и } \\
\text { расширения магистральной инфра- } \\
\text { структуры }\end{array}$ \\
\hline
\end{tabular}

Реализация национальных проектов направлена на улучшение как экономического, так и социального положения страны. При этом выделяются следующие преимущества российских национальных проектов [13]: 1) Комплексный подход; 2) Прозрачность и открытость; 3) Более гибкое государственное планирование и управление; 4) Включение всех уровней государственного управление в процесс реализации национальных проектов.

Выполнение национальных проектов возложено на федеральные и региональные органы власти РФ. Вместе с этим субъекты России 
самостоятельно устанавливают, какие именно проекты будут реализованы на территории их региона. Основным источником средств для реализации нацпроектов являются государственные финансы. Примерный бюджет проектов составляет порядка 25,7 трлн рублей, 30\% из которых представлены внебюджетными инвестициями. В таблице 2 представлено распределение укзанного бюджета [10], согласно которому больший упор делается на экономику и социальное обеспечение граждан.

Таблицуа 2.

Бюджет национальных проектов

\begin{tabular}{|l|c|c|c|}
\hline \multicolumn{1}{|c|}{ Направление } & $\begin{array}{c}\text { Количество } \\
\text { проектов в группе }\end{array}$ & $\begin{array}{c}\text { Бюджет, } \\
\text { трлн руб. }\end{array}$ & В \% к итогу \\
\hline Экономический рост & 6 & 10,1 & $39,3 \%$ \\
\hline Комфортная среда для жизни & 3 & 9,9 & $38,5 \%$ \\
\hline Человеческий капитал & 4 & 5,7 & $22,2 \%$ \\
\hline
\end{tabular}

В таблице 3 приведены результаты работы по реализации нацпроектов по итогам 2019 г. [7].

Таблицча 3.

Данные об исполнении расходов федерального бюджета на реализацию национальных проектов в 2019 году

\begin{tabular}{|l|c|c|}
\hline \multicolumn{1}{|c|}{ Направление } & $\begin{array}{c}\text { Исполнено } \\
\text { на 01.01.2020 г. (млрд руб.) }\end{array}$ & $\begin{array}{c}\text { В \% от бюджета } \\
\text { нацпроектов }\end{array}$ \\
\hline Экономический рост & 558,3 & $5,5 \%$ \\
\hline Комфортная среда для жизни & 273,9 & $2,8 \%$ \\
\hline Человеческий капитал & 768,1 & $13,5 \%$ \\
\hline Всего & 1600,3 & $6,2 \%$ \\
\hline
\end{tabular}

Данные таблицы 2 позволяют сделать вывод о том, что за предыдущий год было израсходовано из бюджета нацпроектов чуть более 6\%. Это указывает на то, что для реализации нацпроектов должны привлекаться более активно частные финансы со стороны внутренних и внешних инвесторов. Именно здесь ключевую роль играет инвестиционная привлекательность региона, поскольку национальные проекты распространяются на все субъекты РФ. В конечном итоге реализация национальных проектов нацелена на раз- 
витие региональной экономики, которые в свою очередь позволят обеспечить рост федеральной экономики в целом [16].

Проведем исследование инвестиционной привлекательности Красноярского края как субъекта для реализации национальных проектов на его территории.

Красноярский край - один из самых крупных субъектов Российской Федерации, расположенный в Сибирском Федеральном округе. Субъект достаточно экономически развит и занимает ключевые позиции в экономической системе всей страны. По объемам валового регионального продукта и инвестиций в основной капитал Красноярский край стабильно входит в первую десятку в рейтинге всех регионов РФ.

Проанализируем инвестиционно привлекательные стороны территории данного субъекта. Для этого рассмотрим ключевые отрасли экономики края. Согласно исследованию ВРП края по видам деятельности, почти половина всего продукта приходится на обрабатывающие и добывающие промышленности (32\% и 26\% соответственно) [2]. Данная информация свидетельствует о том, что субъект является промышленным центром страны. При этом процентная доля таких сфер как сельское хозяйство и наука в ВРП края занимает менее 5\%.

Учитывая, что экономика Красноярского края в большей степени зависит от добычи полезных ресурсов, это нисколько не снижает его инвестиционную привлекательность в глазах инвесторов. Исследование привлекательности, проведённое аналитиками из Национального рейтингового агентства и другими исследователями, показывает, что край инвестиционно развит и его привлекательность находится на среднем уровне с потенциалом последующего роста [4].

К основным конкурентным преимуществам Красноярского края, которые формируют его инвестиционную привлекательность, следует отнести наличие уникального природно-ресурсного потенциала, развитого промышленного комплекса, мощной энергосистемы, крупного транзитного узла, высокого научного и кадрового потен- 
циала [17]. Исходя из этого, отметим, что край достаточно привлекателен для инвесторов из-за высокого потенциала региона.

Реализация инвестиционного потенциала региона осуществляется за счет использования такого инструмента как государственно-частное партнерство (ГЧП). Это долгосрочное ограниченное во времени сотрудничество государственных органов управления и частных организаций в форме интеграции компетенций и интересов власти и бизнеса [14]. ГЧП позволяет направлять инвестиций на реализацию общественно значимых проектов и программ на основе взаимовыгодного сотрудничества. Тем самым с помощью ГЧП органы государственной власти передают сфере бизнеса часть своих обязательств и полномочий по выполнению инвестиционных проектов [18]. Это, в свою очередь, помогает эффективно распределять инвестиционные ресурсы с одной стороны, и в больше объеме выполнять властям свои социальные функции с другой. Если же анализировать инвестиционную привлекательность региона и выполнение национальных проектов на территории субъекта, то именно институт государственночастного партнерства лучше всего подходит для этого.

Так, на территории Красноярского края на данный момент проходит реализация одного из самых масштабных в стране комплексных инвестиционных проектов (КИП) «Енисейская Сибирь». Он включает в себя 27 инвестиционных проектов в различных отраслях экономики, таких как промышленность, сельское хозяйство, транспортная инфраструктура. КИП нацелен на экономический подъем не только Красноярского края, но и республик Хакассия и Тыва. В настоящий момент запланирована реализация 17 инвестиционных проектов общими вложениями в размере 1,4 трлн. руб. Все они будут выполнены в рамках соглашений государственно-частного партнерства с российскими и зарубежными инвесторами [8]. Также за прошедшие несколько лет властями края было заключено около 15 концессионных соглашений с частными инвесторами по развитию социальной сферы региона [6]. Таким образом, в регионе реализуются инвестиционные проекты, выполняемые в рамках соглашений о ГЧП на довольно крупные вложения частного капитала. 
На территории Красноярского края реализуются 12 национальных проектов. За прошлый год объем финансирования нацпроектов составил 20 млрд рублей, при этом на период 2020-2022 годов для реализации национальных проектов будет выделено почти 69 млрд рублей из краевого и федеральных бюджетов. Распределение бюджета нацпроектов представлено на рисунке 1[11].

\section{Реализация}

\section{национальных проектов}

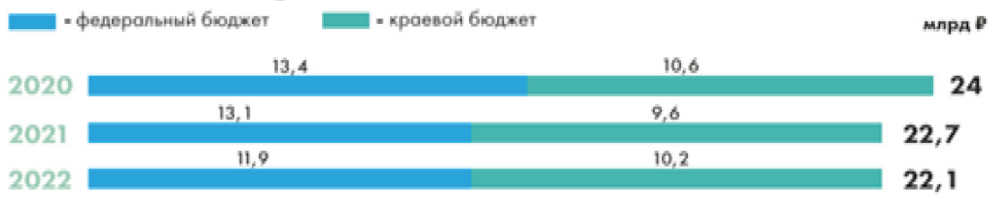

Финансовое обеспечение реализации

национальных проектов на 2020-2022 годы

мпрд 0
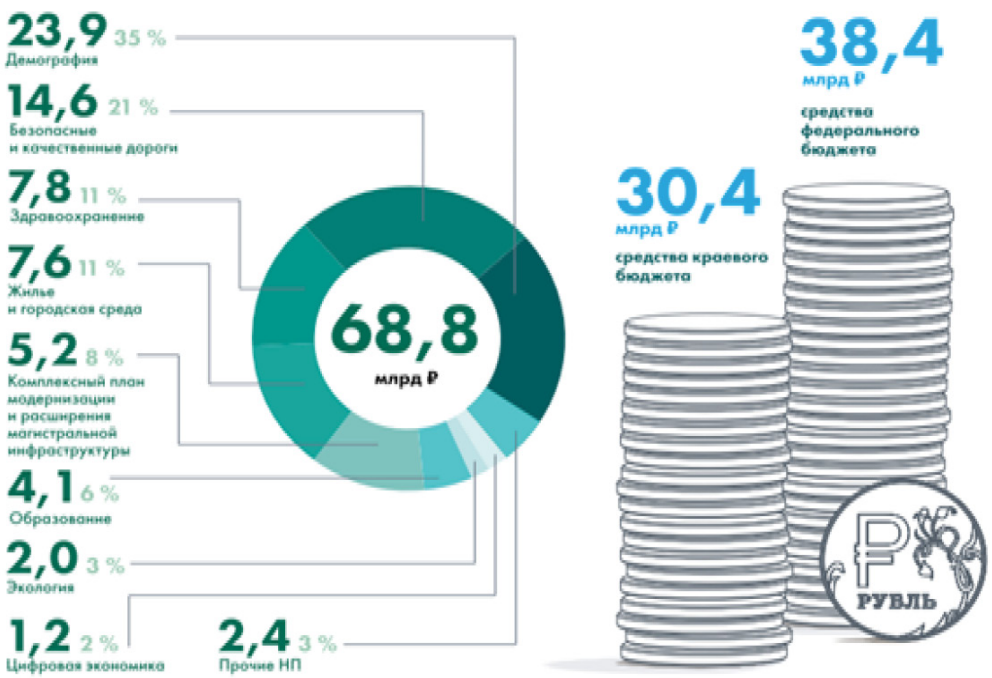

Рис. 1. Бюджет национальных проектов для их реализации на территории Красноярского края в 2020-2022 гг.

Из представленной информации отметим, что основная часть средств бюджета направлена на реализацию социально значимых 
программ. Это может говорить о том, что для реализации проектов, направленных на рост экономического потенциала региона, будут привлечены средства частного капитала.

Наибольшей инвестиционной привлекательностью для бизнеса можно считать национальные проекты «Производительность труда и поддержка занятости», «Международная кооперация и экспорт», «Цифровая экономика».

Исследуем, как совместное сотрудничество государства и бизнеса способствуют реализации наиболее привлекательных для бизнеса нацпроектов. Рассматривая проект «Производительность труда и поддержка занятости» следует отметить, что региональные власти заинтересованы в поддержке как бизнеса, так и населения для экономического роста субъекта. При этом если для бизнеса будут обеспечены благоприятные условия ведения их деятельности со стороны властей, то тогда они смогут наращивать объемы производства, создавать новые рабочие места и привлекать инвестиции в развитие своего предприятия. В конечном итоге, это позволит развиваться региональной экономике. По итогам 2019 года в крае заключены соглашения о реализации мероприятий национального проекта с 23 предприятиями, что позволило на $30 \%$ увеличить объем выпуска готовой продукции, в 1,5 раза сократить время выпуска готовой продукции [12]. Такие результаты работы могут говорить о положительном эффекте данного нацпроекта для предприятий края, впоследствии будет возможным дополнительных частных инвестиций в нацпроект.

Остановимся на реализации проекта «Цифровая экономика». Инвестиционной привлекательностью данный нацпроект пользуется, в первую очередь, для компаний коммуникационного сектора. Власти региона заинтересованы в том, чтобы предоставлять населению доступ к качественной мобильной связи и сети Интернет. Обеспечивать такие возможности могут частные компании, например, операторы сотовой связи. Предоставление налоговых льгот и других преимуществ со стороны государства в обмен на инвестиции бизнеса, направленных в цифровой сектор экономики, будут способствовать эффективной реализации нацпроекта. 
Нацпроект «Международная кооперация и экспорт» достаточно привлекателен не только для добывающих предприятий края, но и для отраслей агропромышленного комплекса (АПК) и туризма. Поскольку Красноярский край достаточно большой по площади, то он обладает хорошим потенциалом для компаний АПК, особенно в южных районах субъекта. Об этом свидетельствуют результаты реализации нацпроекта в 2019 году, в которых указано, что сельскохозяйственная продукция края экспортируется не только в регионы РФ, но и во многие иностранные государства. При этом Красноярский край обладает высоким потенциалом для туристической деятельности. На территории региона расположены заповедники, национальный парк, созданы 3 туристско-рекреационные зоны [12]. Данные особенности субъекта могут быть инвестиционно привлекательными для внутреннего и зарубежного туристического бизнеса.

\section{Выводы}

Результаты реализации нацпроектов на территории Красноярского края свидетельствуют об участии бизнеса, поскольку край достаточно привлекателен для инвесторов высоким инвестиционным потенциалом. Грамотное привлечение и эффективное использование вложений частного капитала способно оказать благоприятное воздействие на рост экономики не только субъектов РФ, но и всей страны.

Повышение заинтересованности со стороны властей регионов посредством создания благоприятного инвестиционного климата, а также использования принципов государственно-частного партнерства позволит расширить потенциал источников финансирования нацпроектов. Одним из возможных инструментов привлечения бизнеса в инвестирование нацпроектов является предоставление налоговых льгот со стороны региональных властей, что обеспечит частным компаниям выход на новые рынки сбыта товаров и услуг.

Конечно, стоит отметить, что реализация программ государственно-частного партнерства более эффективно возможно в условиях экономического благополучия региона и всей страны в целом. Учи- 
тывая тот факт, что на данный момент времени экономическое положение нашего государства находится не в самом благоприятном положении из-за ограничений, вызванных пандемией, то это, непосредственно, отразилось на институте государственно-частного партнерства. Информация из открытых источников свидетельствует о снижении объема привлекаемых инвестиций в программы ГЧП: 708 млрд. руб. в 2019 году и 131 млрд. рублей в 2020 году [9].

Принимая это во внимание, хочется надеяться на то, что государственные и региональные власти примут все необходимые меры для поддержания рынка ГЧП, чтобы привлечение вложений частного капитала в исполнение национальных проектов было возможным.

\section{Список литературы}

1. Будущее России. Национальные проекты. https://futurerussia.gov.ru/ about (дата обращения 25.07.2020).

2. Валовой региональный продукт в основных ценах (ОКВЭД-2007). https://fedstat.ru/indicator/33379 (дата обращения 25.07.2020).

3. Джиоев В.А. Сущность и взаимосвязь понятий инвестиционной привлекательности и инвестиционного климата регионов // Вестник ГУУ. 2020. №3. С. 118-122.

4. Дубровская Т.В. Особенности анализа инвестиционной привлекательности регионов Сибири (на примере Красноярского края) // Вестник СИБИТа. 2019. №2. С. 49-54.

5. Жукова Н.Ю., Цыкарева Е.В. Региональная политика продвижения бренда территорий: детерминанты инвестиционной привлекательности // Вопросы государственного и муниципального управления. 2017. №4. C. 173-206.

6. Инвестиционный портал Красноярского края. Государственно-частное партнёрство. http://krskinvest.ru/ru/pages/obshchie-svedeniya-ogchp (дата обращения 03.08.2020).

7. Исполнение федерального бюджета и бюджетов бюджетной системы Российской Федерации за 2019 год.https://www.minfin.ru/ru/ perfomance/budget/federal_budget/budgeti/2019/ (дата обращения 25.07.2020). 
8. КИП «Енисейская Сибирь». Проекты. https://ensib.ru/projects (дата обращения 03.08.2020).

9. Коммерсантъ. Рынок ГЧП-проектов вернулся в 2010 год. https:// www.kommersant.ru/doc/4509843 (дата обращения 29.09.2020).

10. Новиков А.В., Новиков И.Я. Развитие финансового рынка как драйвер роста экономики России // Идеи и идеалы. 2020. № 1-2. С. 319 352.

11. Путеводитель по бюджету Красноярского края 2020. http://minfin. krskstate.ru/openbudget/book (дата обращения 25.07.2020).

12. Реализация национальных проектов в Красноярском крае. http:// www.project.krskstate.ru/nacprojects (дата обращения 25.07.2020).

13. Слепцова Е.В., Пруидзе А. Влияние национальных проектов на повышение качества жизни граждан РФ // Экономика и бизнес: теория и практика. 2020. №2-2. С. 117-119.

14. Khidoyatov D.A. Features of public-private partnership projects financing // European science review. 2019. №1-2. C. 195-200.

15. Mustafokulov O. A. Theoretical aspects of increasing regional investment economic attractiveness // Science and Practice Bulletin. 2018. №3. C. 203-210.

16. Ruiga I.R., Kovzunova E.S., Stupina A.A., Kashina E.V., Burmenko T.A. Improvement of the methodological approaches to the evaluation of the agro-industrial clusters development potential in the regional economy // II international scientific conference «AGRITECH-II-2019: agribusiness, environmental engineering and biotechnologies». 2019. DOI: 10.1088/1755-1315/421/3/032053.

17. Ruiga I.R., Stupina A.A., Kovzunova E.S., Chayka A.A., Shkradyuk I.A. Practical implementation of data envelopment analysis technology to assess the innovative sustainability of resource-type regions // International scientific conference "Conference on applied physics, information technologies and engineering - APITECH-2019”. 2019. DOI: 10.1088/1742-6596/1399/3/033118.

18. Vasylieva N.V., Vasylieva O.I. Public private partnership as a tool for development of territories // Public governance. 2019. №2 (17). C. 34-44. DOI: 10.32689/2617-2224-2019-17-2-34-44. 


\section{References}

1. The future of Russia. National projects. https://futurerussia.gov.ru/about (accessed 07/25/2020).

2. Gross regional product in basic prices (OKVED-2007). https://fedstat. $\mathrm{ru} /$ indicator/33379 (accessed 07/25/2020).

3. Dzhioyev V.A. Sushchnost' ivzaimosvyaz' ponyatiy investitsionnoy privlekatel'nostii investitsionnogo klimatar egionov [The essence and relationship of the concepts of investment attractiveness and the investment climate of the regions].Vestnik GUU. 2020. no. 3, pp. 118-122.

4. Dubrovskaya T.V. Osobennosti analiza investitsionnoy privlekatel'nostiregiono v Sibiri (na primere Krasnoyarskogo kraya) [Features of the analysis of investment attractiveness of Siberian regions (on the example of the Krasnoyarsk Territory)]. Vestnik SIBITa. 2019. no. 2, pp. 49-54.

5. Zhukova N.Yu., Tsykareva Ye.V. Regional'naya politika prodvizheniya Brenda territoriy: determinant investitsionnoy privlekatel'nosti [Regional policy of promoting the brand of territories: determinants of investment attractiveness]. Voprosy gosudarstvennogo i munitsipal'nogo upravleniya. 2017. no. 4, pp. 173-206.

6. Investment portal of the Krasnoyarsk Territory. Public-private partnership. http://krskinvest.ru/ru/pages/obshchie-svedeniya-o-gchp (accessed 08/03/2020).

7. Execution of the federal budget and the budgets of the budgetary system of the Russian Federation for 2019. https://www.minfin.ru/ru/perfomance/budget/federal_budget/budgeti/2019/ (accessed 25.07.2020).

8. KIP "Yenisei Siberia". Projects. https://ensib.ru/projects (accessed 08/03/2020).

9. Kommersant. The PPP project market returned to 2010. https://www. kommersant.ru/doc/4509843 (appeal date 09/29/2020).

10. Novikov A. V., NovikovI. Ya. Razvitiye finansovogo rynka kak drayver rosta ekonomiki Rossii [Financial market development as a growth driver for the Russian economy]. Idei i idealy. 2020. no. 1-2, pp. 319-352.

11. Guide to the budget of the Krasnoyarsk Territory 2020. http://minfin. krskstate.ru/openbudget/book (accessed 07/25/2020). 
12. Implementation of national projects in the Krasnoyarsk Territory http:// www.project.krskstate.ru/nacprojects (accessed 07/25/2020).

13. Sleptsova Ye. V., Pruidze A. Vliyaniye natsional'nykh proyektov na povysheniye kachestva zhizni grazhdan RF [The impact of national projects on improving the quality of life of citizens of the Russian Federation]. Ekonomika i biznes: teoriya i praktika. 2020. no. 2-2, pp. 117-119.

14. Khidoyatov D. A. Features of public-private partnership projects financing.European science review. 2019. no. 1-2, pp. 195-200.

15. Mustafokulov O.A. Theoretical aspects of increasing regional investment economic attractiveness. Science and Practice Bulletin. 2018. no. 3, pp. 203-210.

16. Ruiga I.R., Kovzunova E.S., Stupina A.A., Kashina E.V., Burmenko T.A. Improvement of the methodological approaches to the evaluation of the agro-industrial clusters development potential in the regional economy. II international scientific conference "AGRITECH-II-2019: agribusiness, environmental engineering and biotechnologies». 2019. DOI: $10.1088 / 1755-1315 / 421 / 3 / 032053$

17. Ruiga I.R., Stupina A.A., Kovzunova E.S., Chayka A.A., Shkradyuk I.A. Practical implementation of data envelopment analysis technology to assess the innovative sustainability of resource-type regions. International scientific conference "Conference on applied physics, information technologies and engineering - APITECH-2019”. 2019. DOI: 10.1088/1742-6596/1399/3/033118.

18. Vasylieva N.V., Vasylieva O.I. Public private partnership as a tool for development of territories. Public governance. 2019. no. 2, pp. 34-44. DOI: 10.32689/2617-2224-2019-17-2-34-44

\section{ДАННЫЕ ОБ АВТОРАХ}

Бутакова Нина Михайловна, доцент кафедры «Экономическая и финансовая безопасность», кандидат экономических наук Сибирский Федеральный университет, Институт управления бизнес-прочессами и экономики ул. Ак. Киренского, 26А, г. Красноярск, 660074, Российская Федерация ninabytakova@mail.ru 
Кудашкин Илья Валерьевич, студент

Сибирский Федеральньй университет, Институт управления бизнес-прочессами и экономики

ул. Ак. Киренского, 26А, г. Красноярск, 660074, Российская Федерация

ilja3110@mail.ru

\section{DATA ABOUT THE AUTHORS}

Butakova Nina Mikhailovna, Associate Professor of the Department "Economic and financial security", Candidate of Economic Sciences Siberian Federal University, Institute of Business Process Management and Economics 26A, Kirensky Str., Krasnoyarsk, 660074, Russian Federation ninabytakova@mail.ru

Kudashkin Ilya Valerievich, student

Siberian Federal University, Institute of Business Process Management and Economics 26A, Kirensky Str., Krasnoyarsk, 660074, Russian Federation ilja3110@mail.ru 